\title{
Correction to: Synthetic low-strength materials as rock substitutes for physical model studies
}

\author{
Farzin Hamidi $₫$ - Alexander Scheuermann - Sergio Andres Galindo-Torres • \\ Dorival Pedroso $\cdot$ Ling Li
}

Published online: 27 February 2018

(C) Springer International Publishing AG, part of Springer Nature 2018

\section{Correction to: Geomechanics and Geophysics for Geo-Energy and Geo-Resources https://doi.org/10.1007/s40948-018- 0083-9}

In the initial online publication there was a typesetting mistake: In the part of Table 8 that continues onto the next page of this article the columns had shifted to the left for the first 6 rows. The original article has been corrected.

The original article can be found online at https:// doi.org/10.1007/s40948-018-0083-9.

F. Hamidi $(\square) \cdot$ A. Scheuermann · S. A. Galindo-Torres

Geotechnical Engineering Centre, School of Civil

Engineering, The University of Queensland, Brisbane,

QLD 4072, Australia

e-mail: Farzin.hamidi@uq.net.au

A. Scheuermann

e-mail: a.scheuermann@uq.edu.au

S. A. Galindo-Torres

e-mail: s.galindotorres@uq.edu.au

\section{S. A. Galindo-Torres}

School of Engineering, The University of Liverpool,

Liverpool, UK

D. Pedroso - L. Li

School of Civil Engineering, The University of

Queensland, Brisbane, QLD 4072, Australia

e-mail: d.pedroso@uq.edu.au

L. Li

e-mail:1.1i@uq.edu.au 